\title{
The mycorrhizal species of Rhizoctonia
}

Andersen, Torben Frank; Rasmussen, Hanne Nina

Published in:

Rhizoctonia species

Publication date:

1996

Citation for published version (APA):

Andersen, T. F., \& Rasmussen, H. N. (1996). The mycorrhizal species of Rhizoctonia. In B. Sneh, S. JabajiHare, S. Neate, \& G. Dijst (Eds.), Rhizoctonia species: Taxonomy, Molecular biology, Ecology, Pathology and Disease control (pp. 379-390). Kluwer Academic Publishers. 

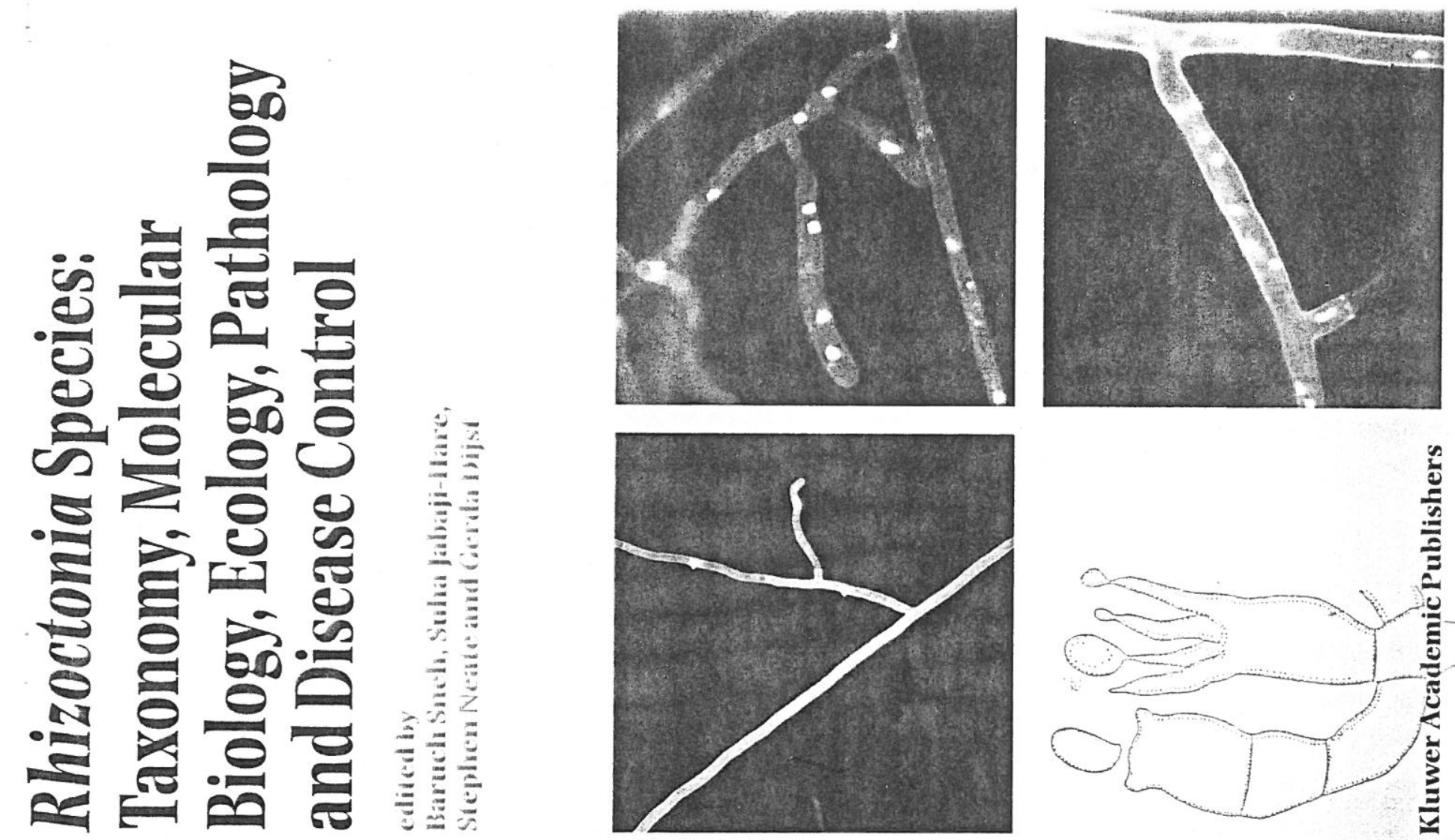

Rhizoctonia Species:

Taxonomy, Molecular Biology, Ecology, Baruch Sneh. Suha Jabaji-tiare, Pathology and Disease Control

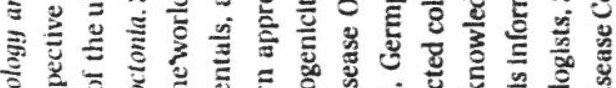

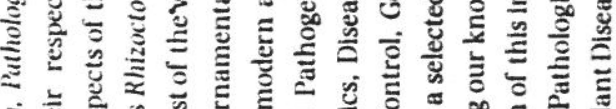

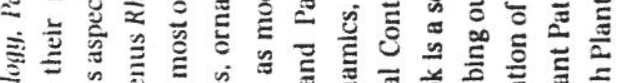

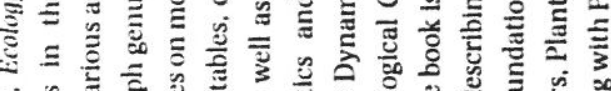

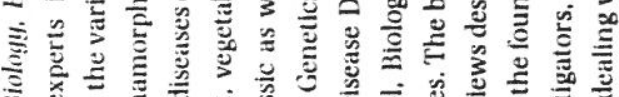

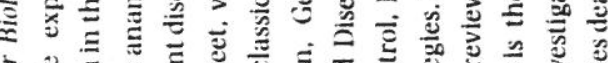

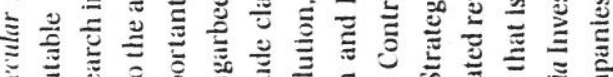

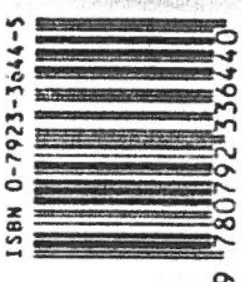

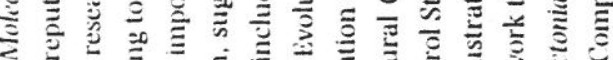

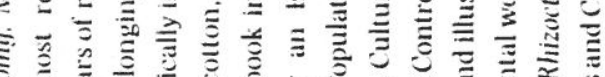

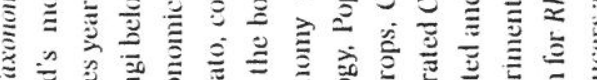

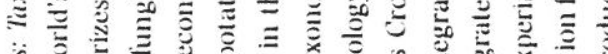

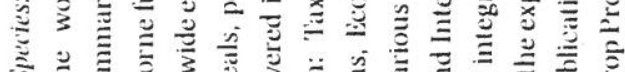

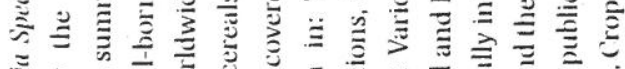

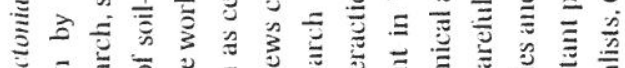

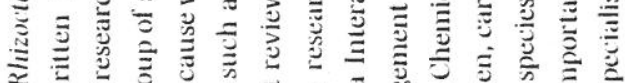

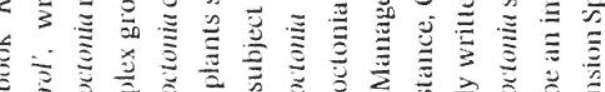

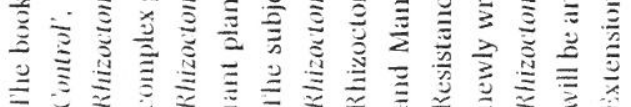




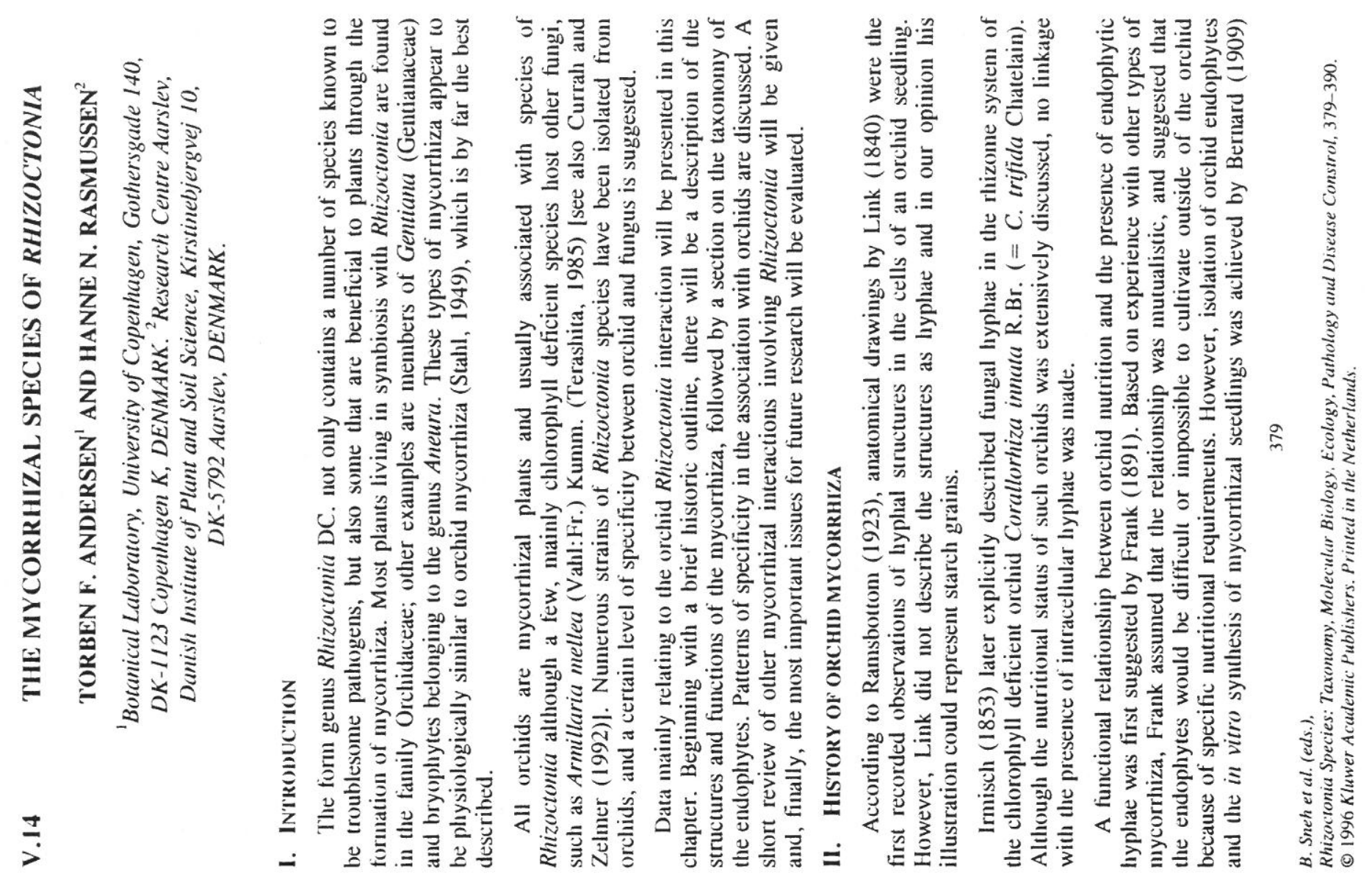




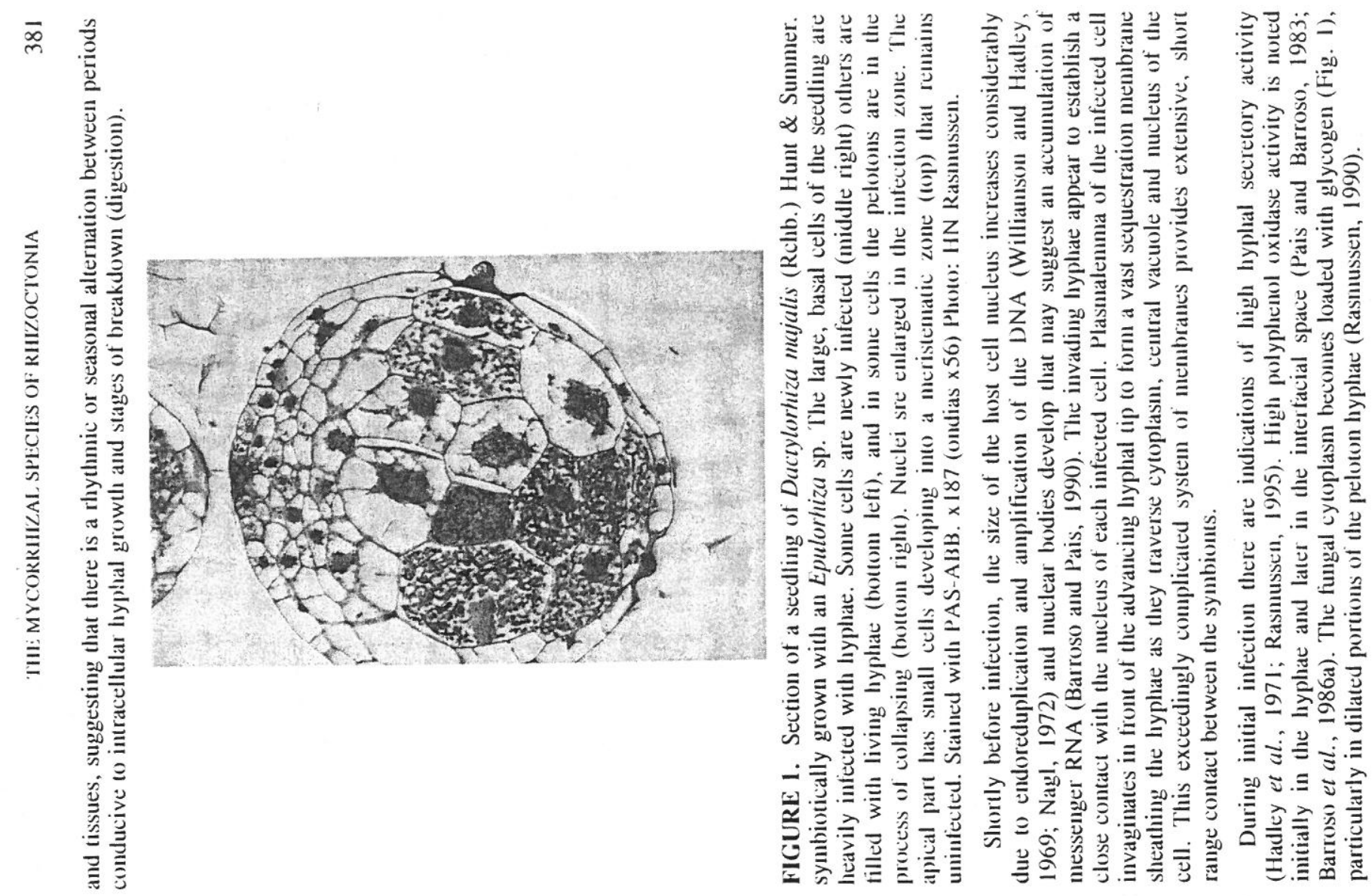

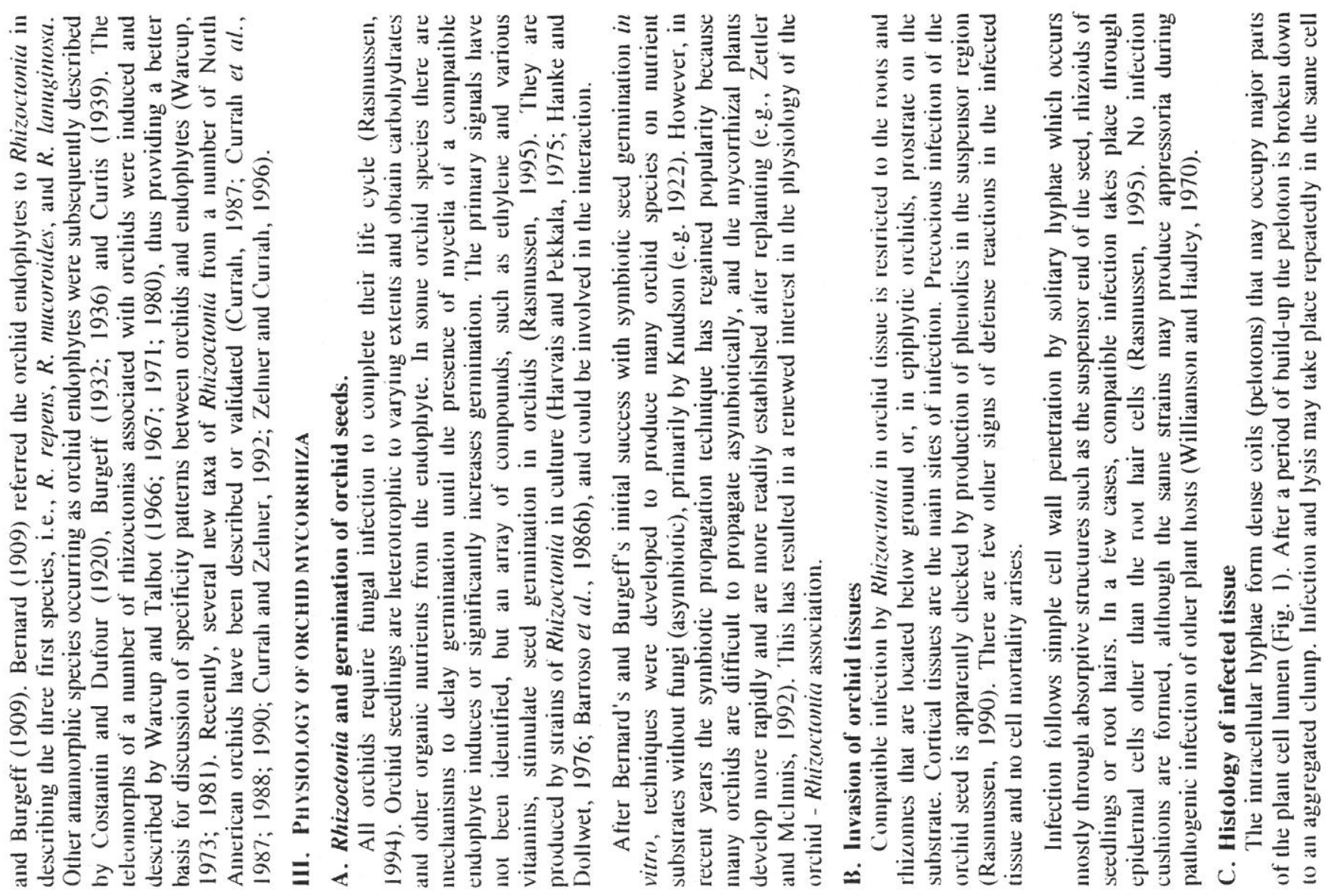




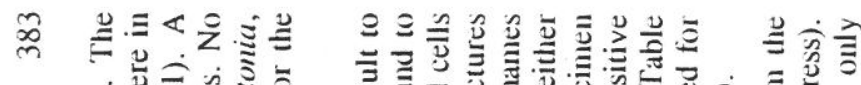

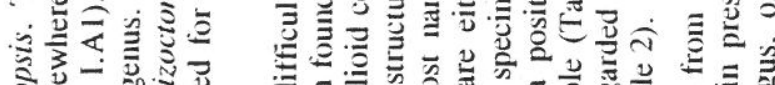

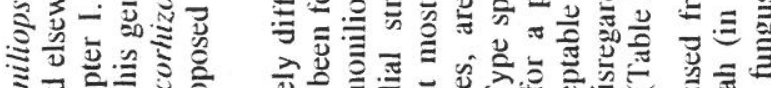

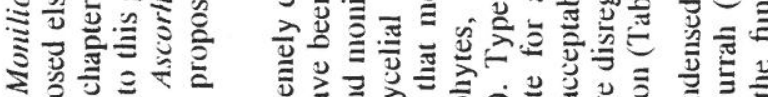

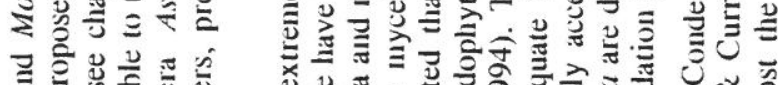

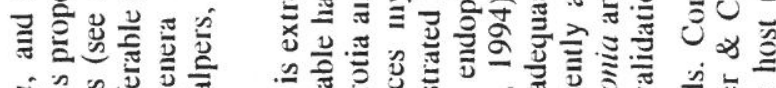

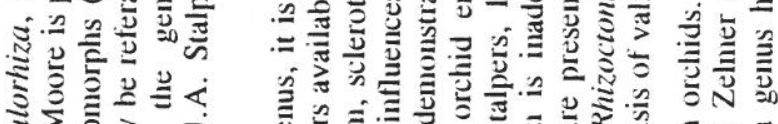

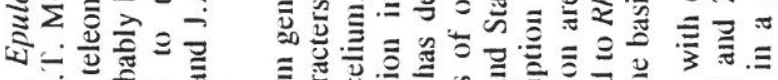

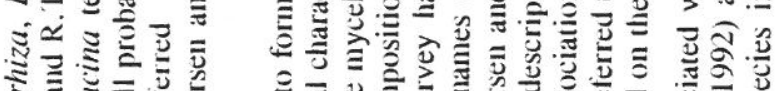

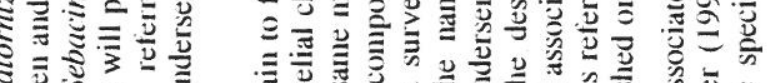

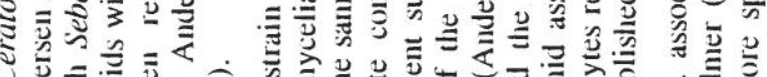

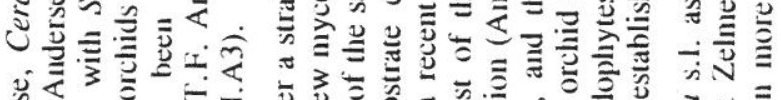

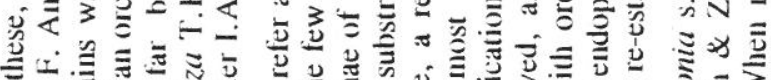

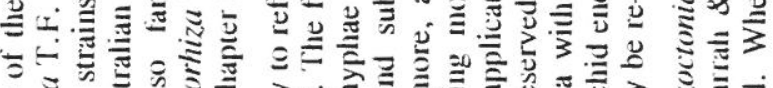

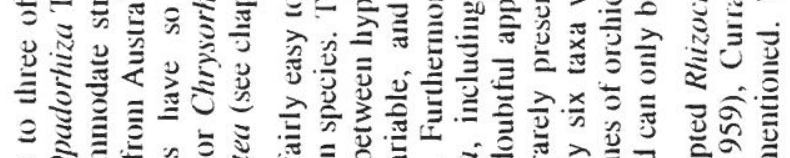
气

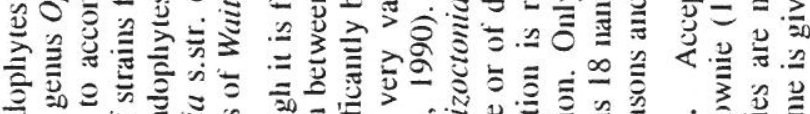

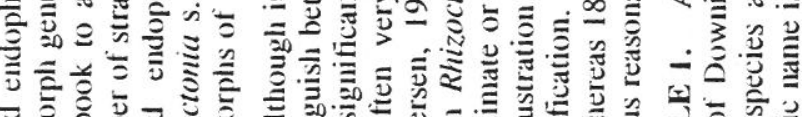

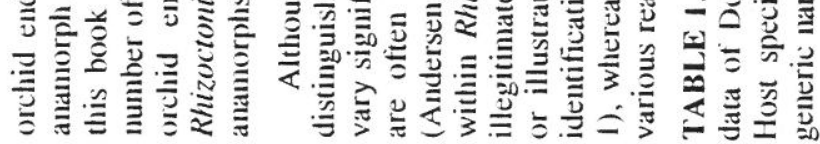

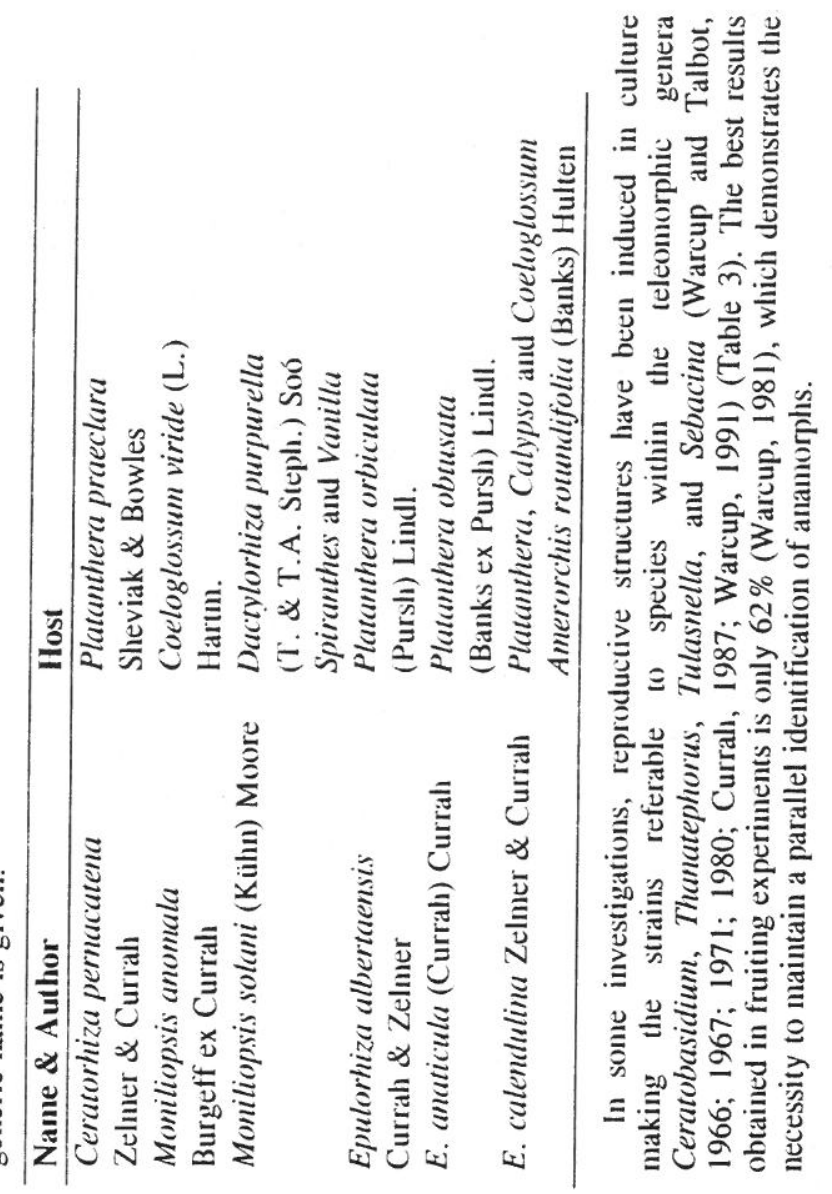

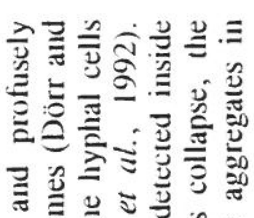

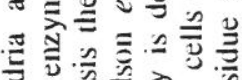

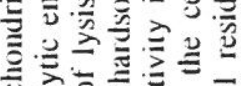

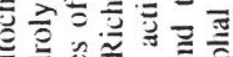

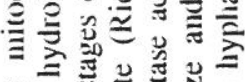

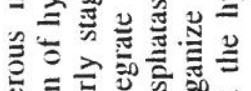

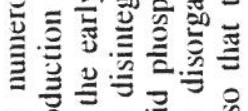

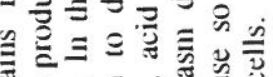

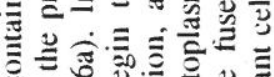

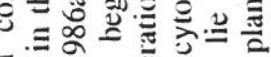

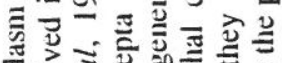

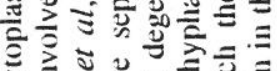

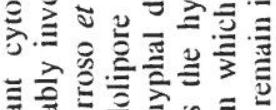

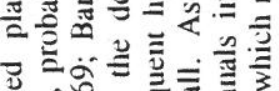

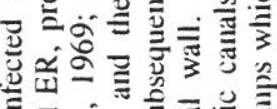

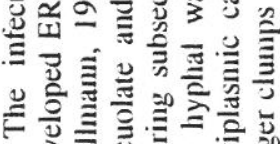

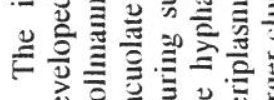

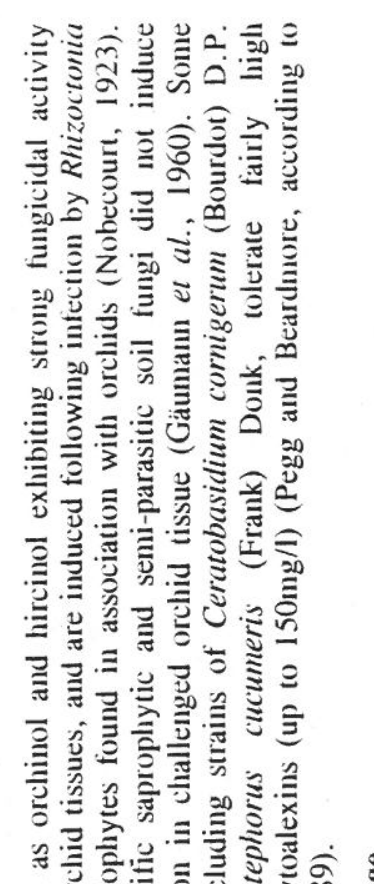

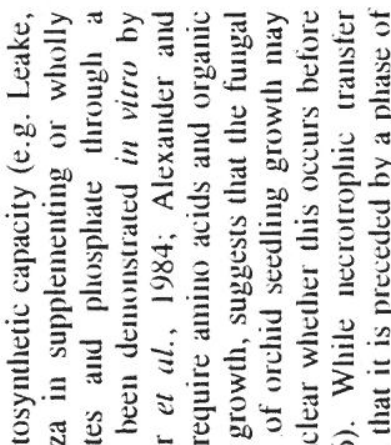

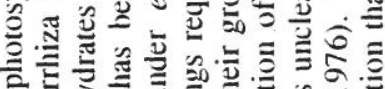
일

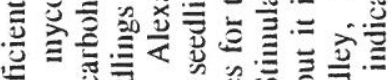

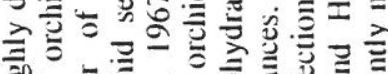

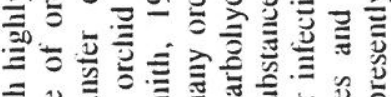

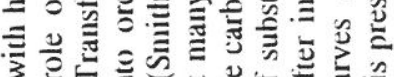

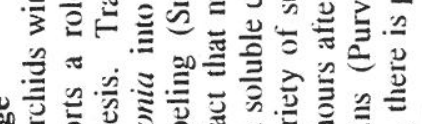

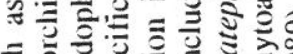

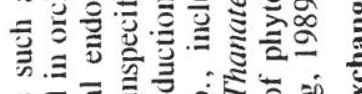

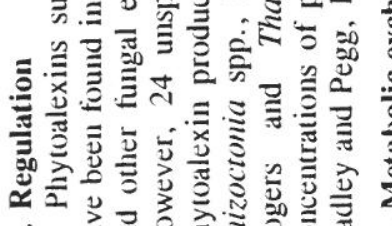

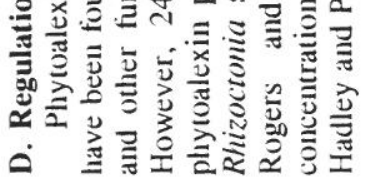

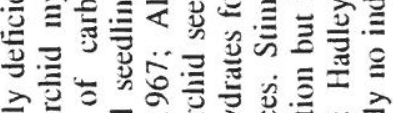

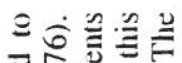

를을.

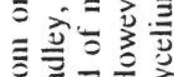

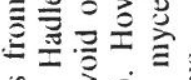

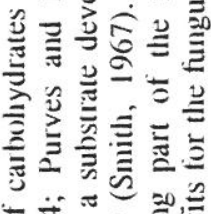

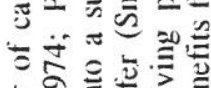

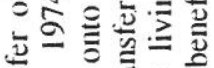

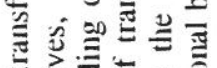

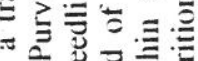

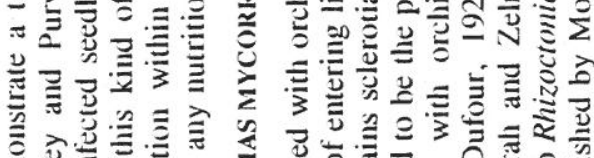

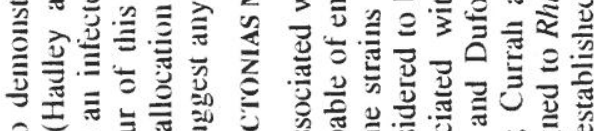

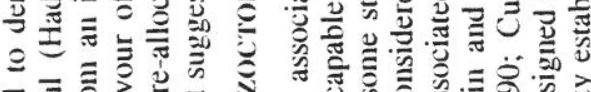

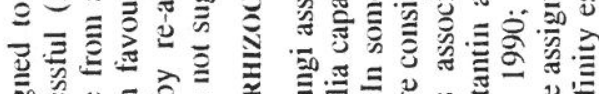

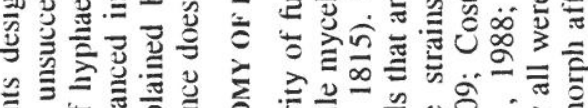

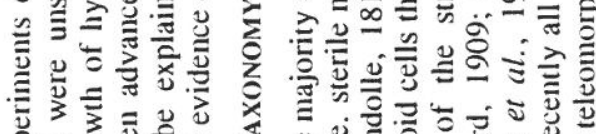

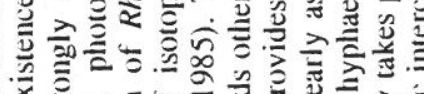

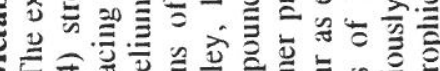

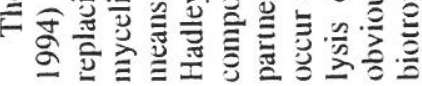

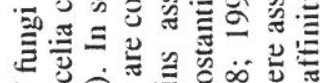

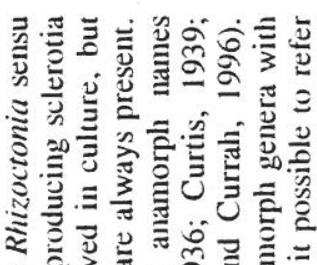

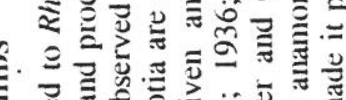

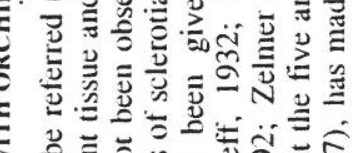

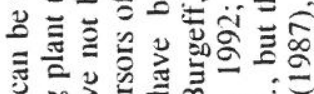

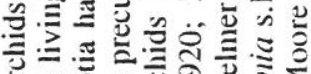

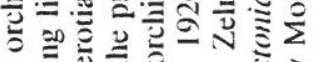

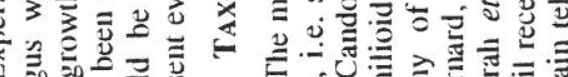

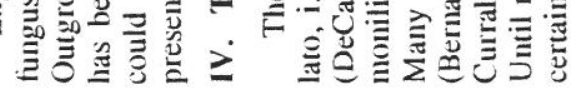
20글 


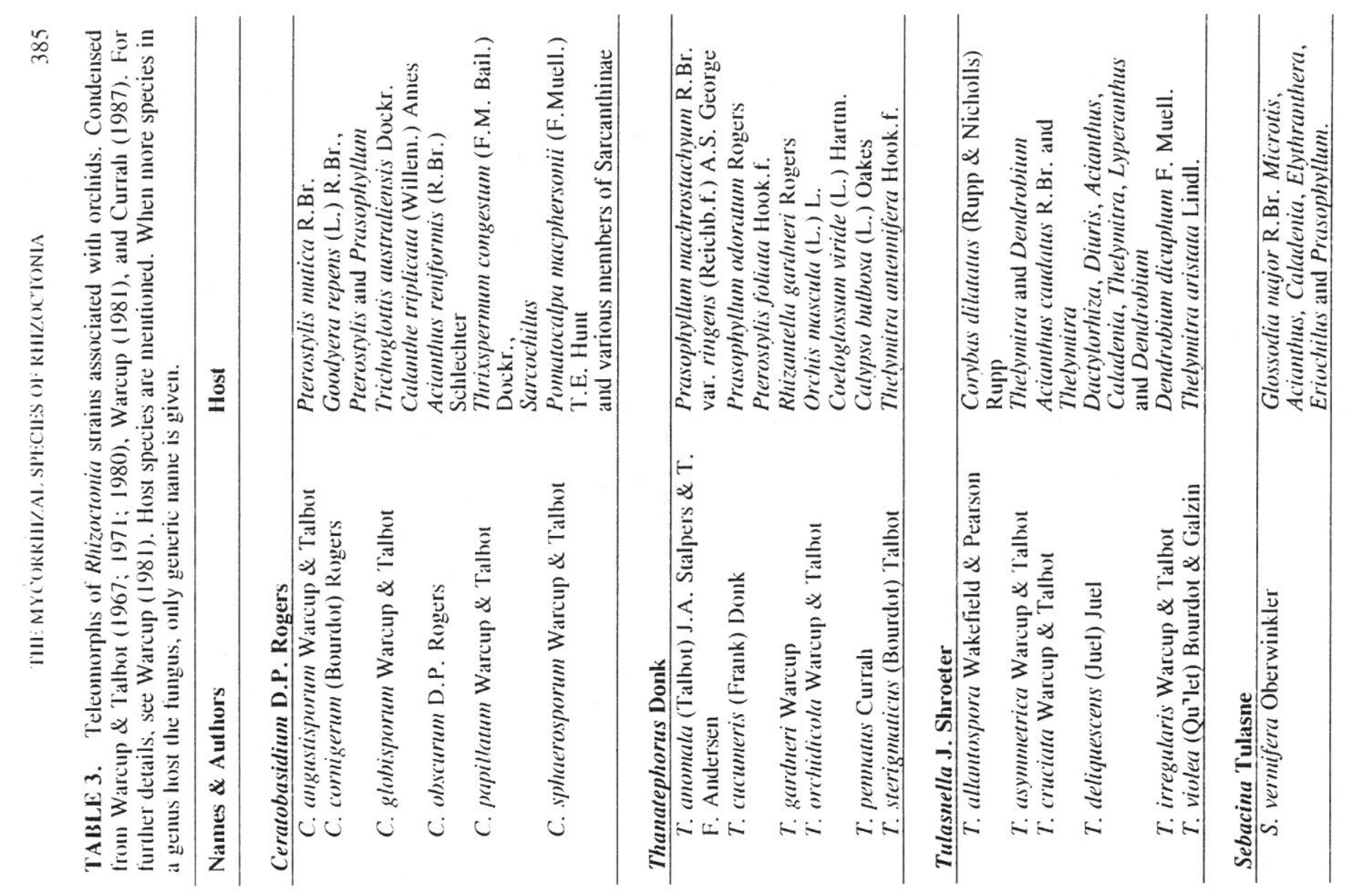

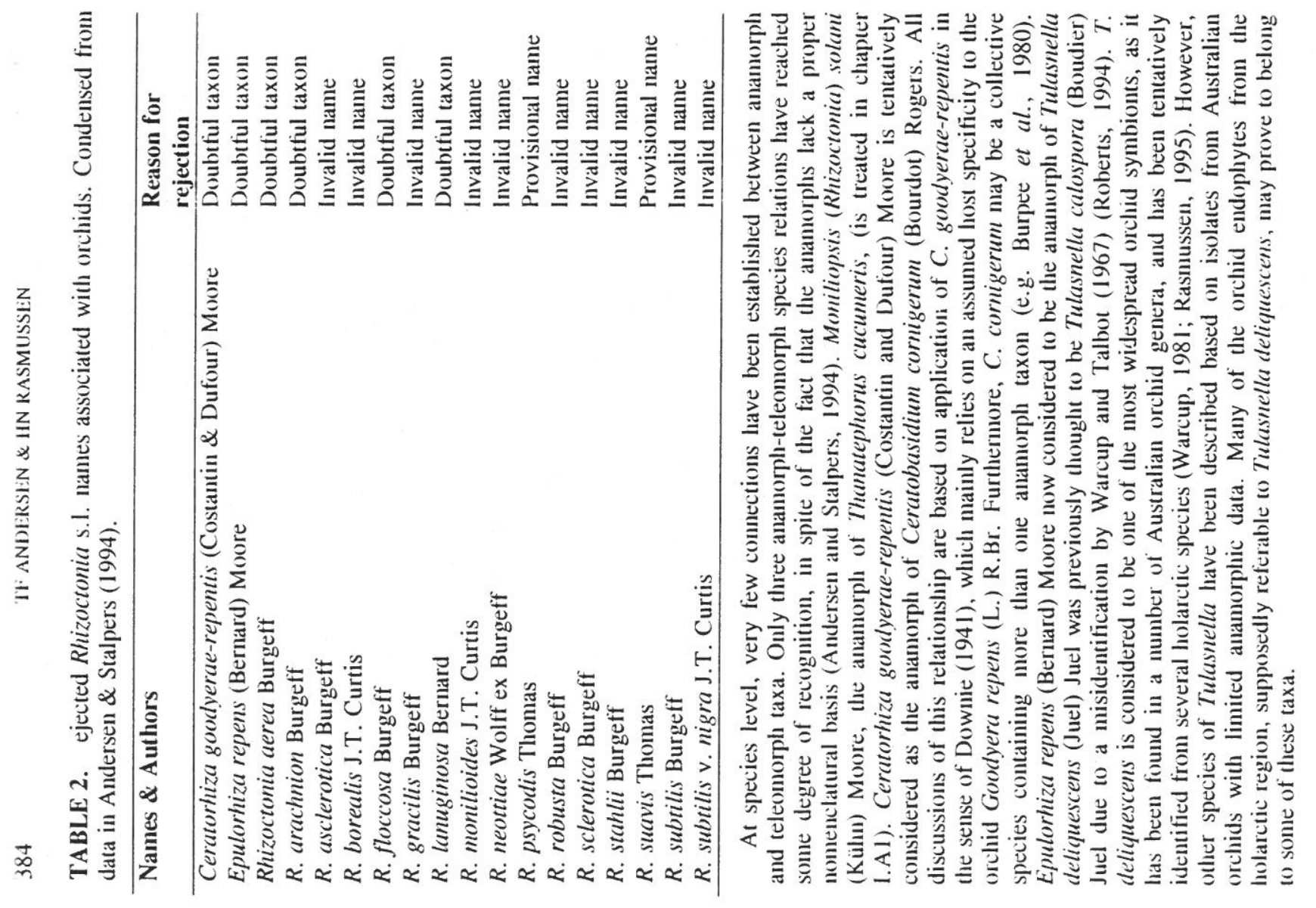




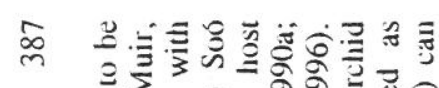

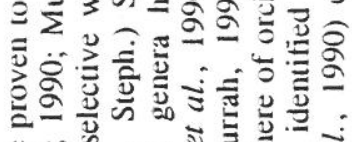

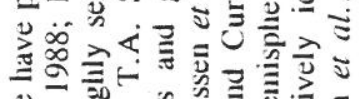

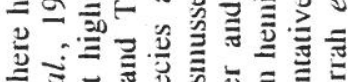

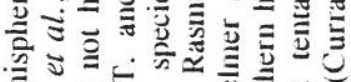

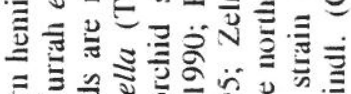

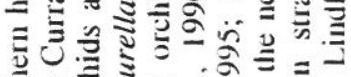

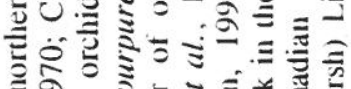

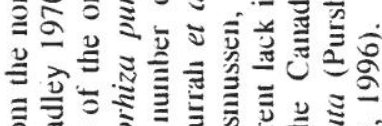

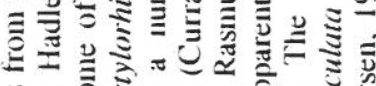

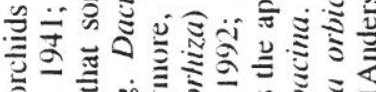

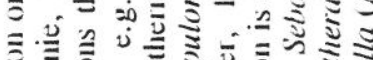

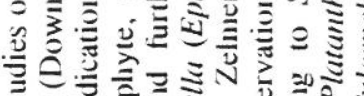

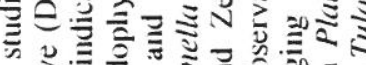

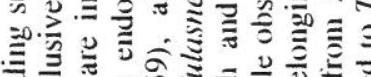

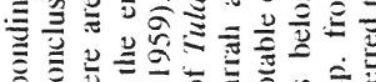

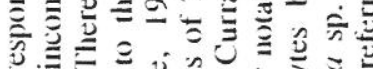

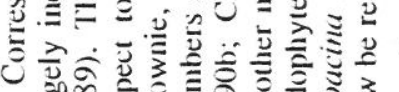

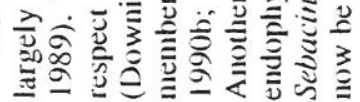

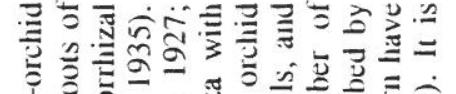

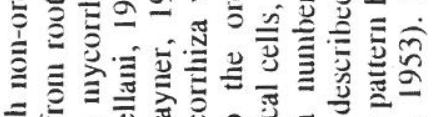

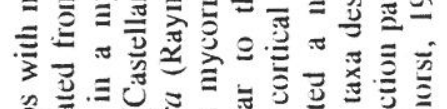

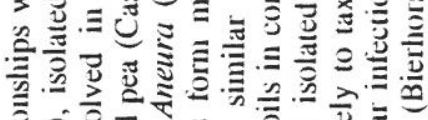

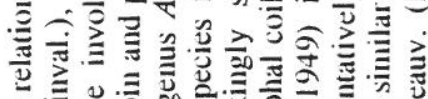

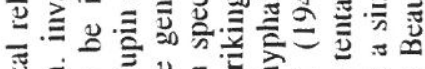

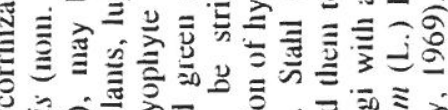
0
0

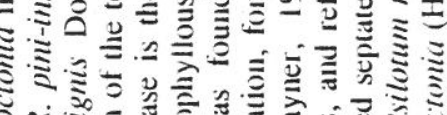

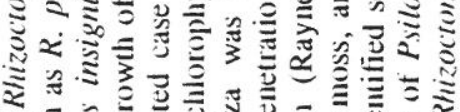

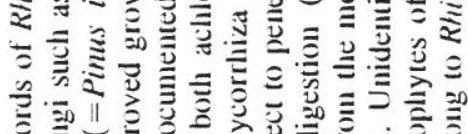

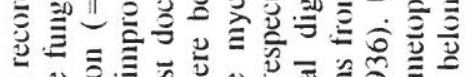

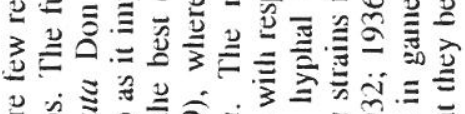

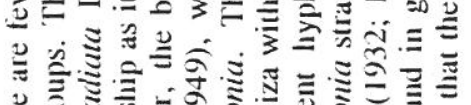

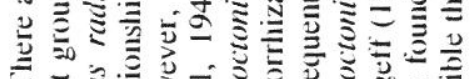

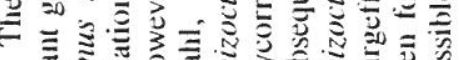

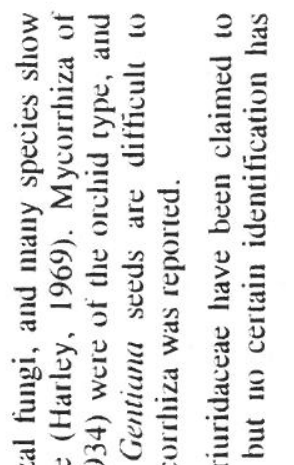

可证言

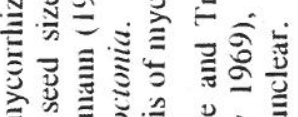
0
0

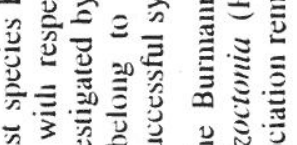

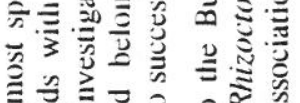

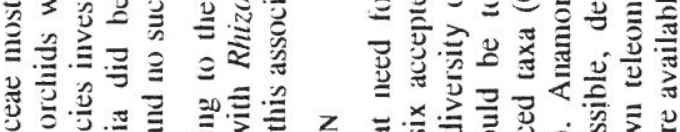

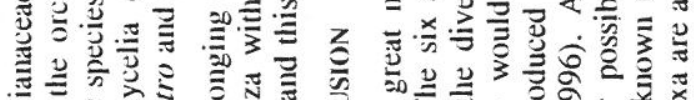

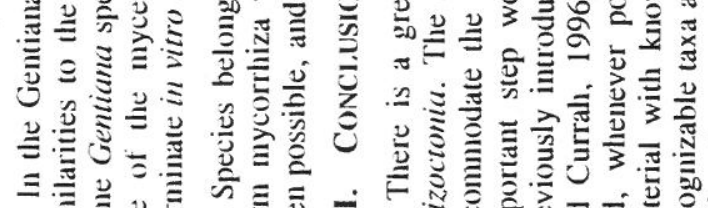

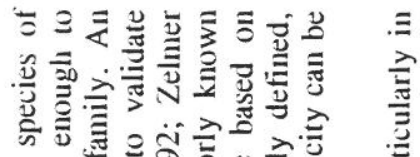

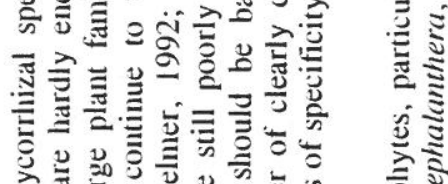

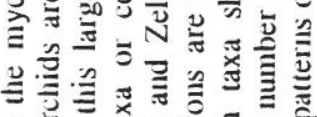

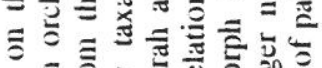

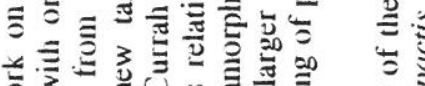

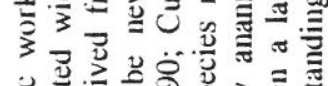

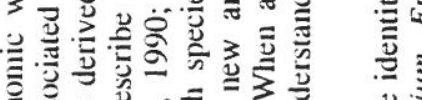

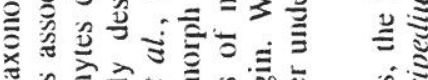

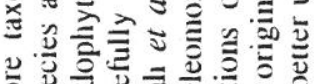

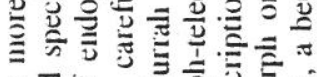

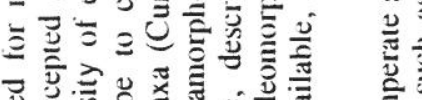
政产 赔 产

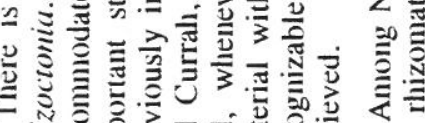

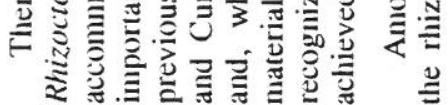

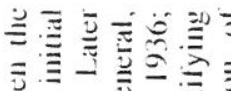

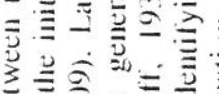
ป气

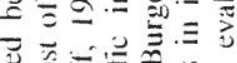

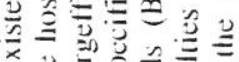

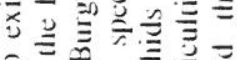

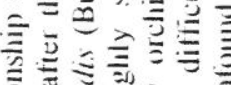

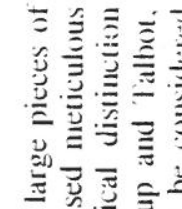

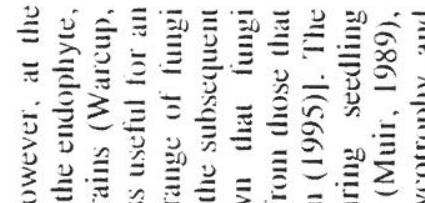

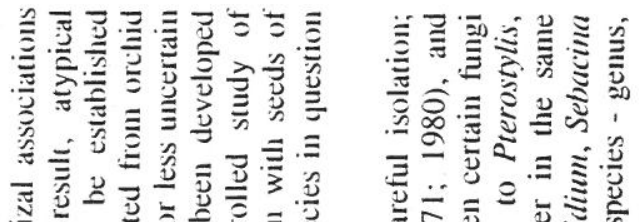

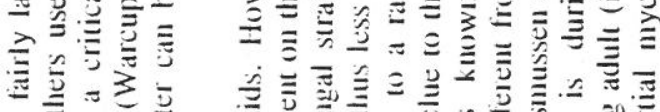

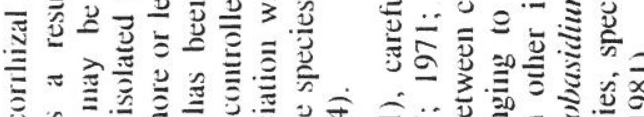

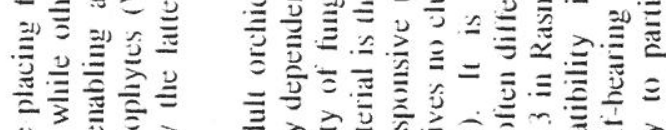

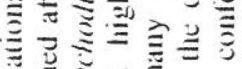

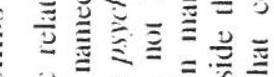

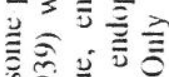

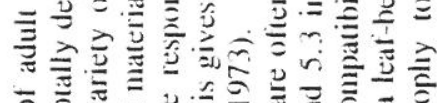

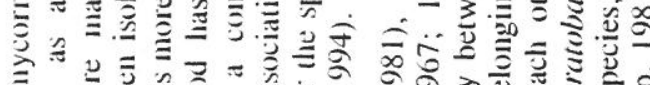

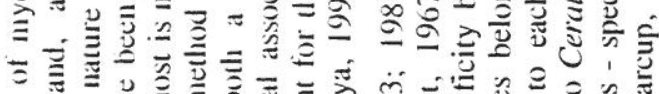

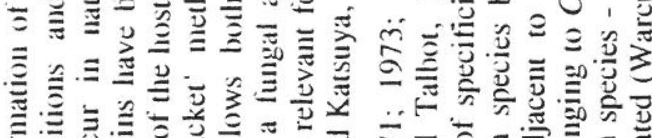

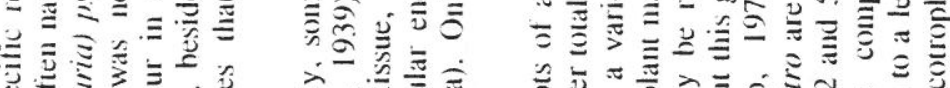

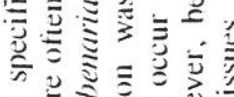

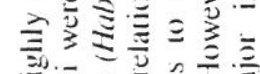

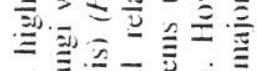

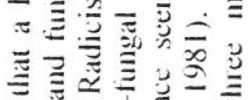

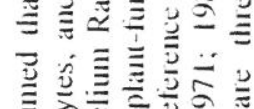

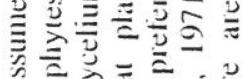

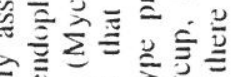

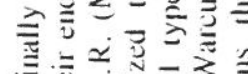

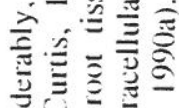

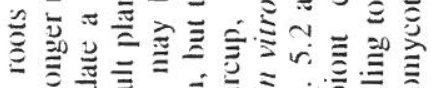

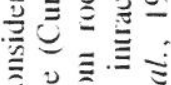

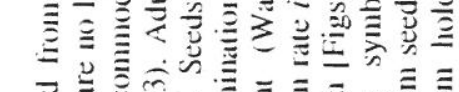

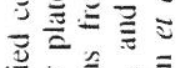

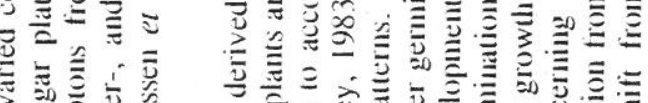

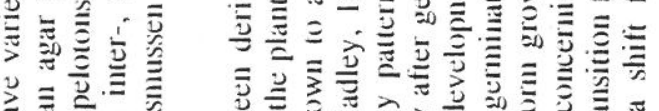

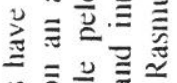

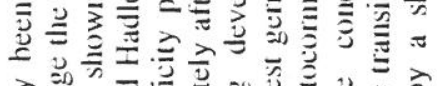

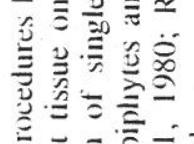

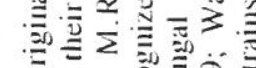

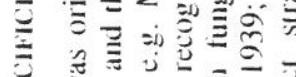

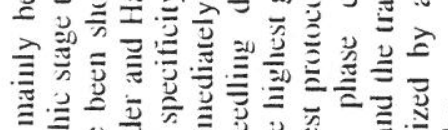

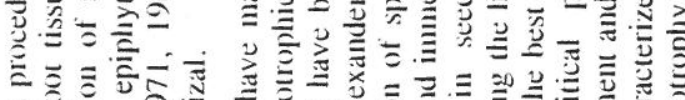

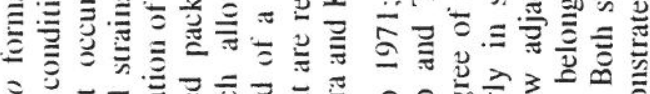

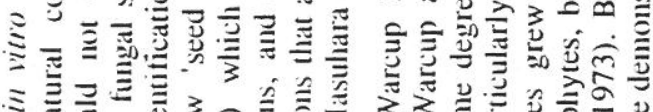

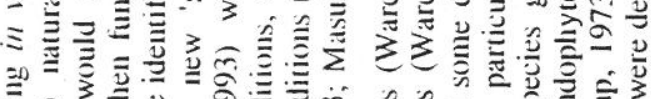

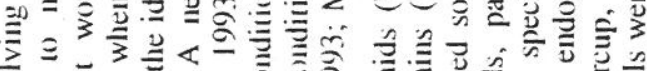

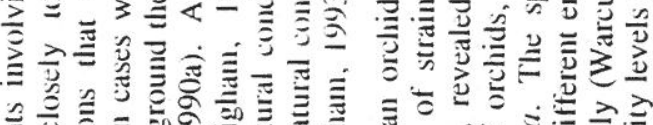

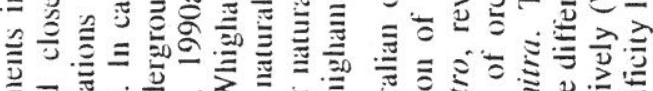

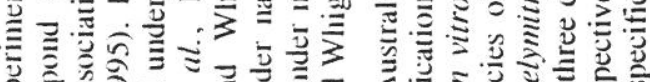

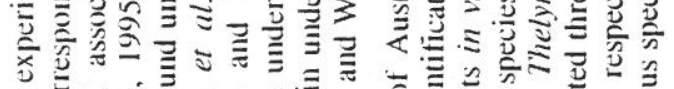

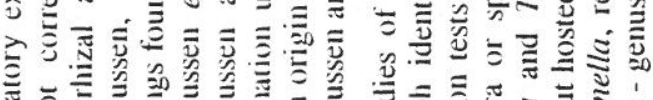

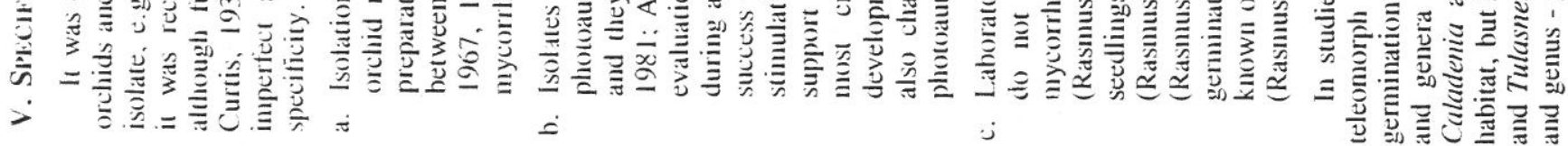




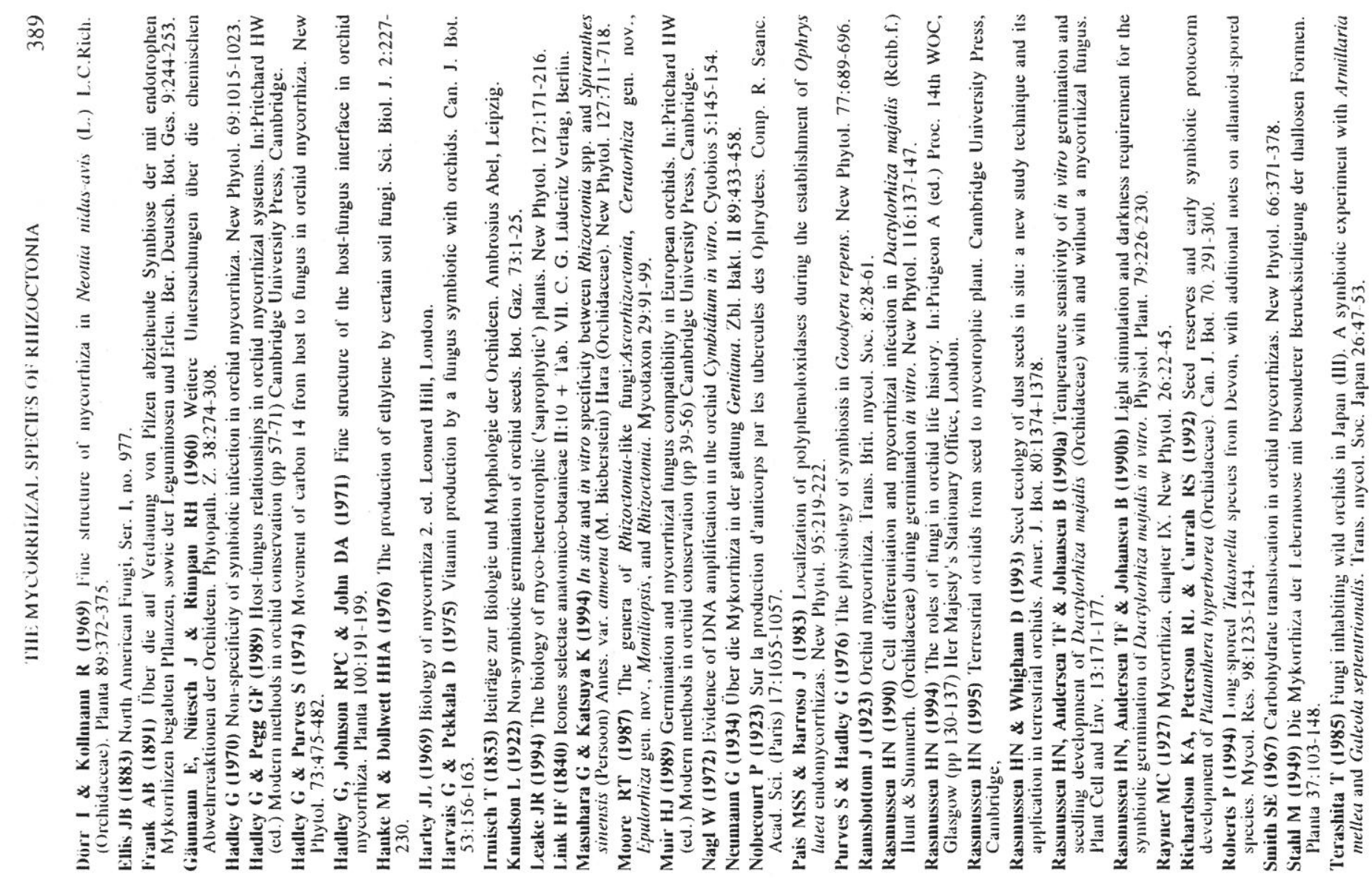

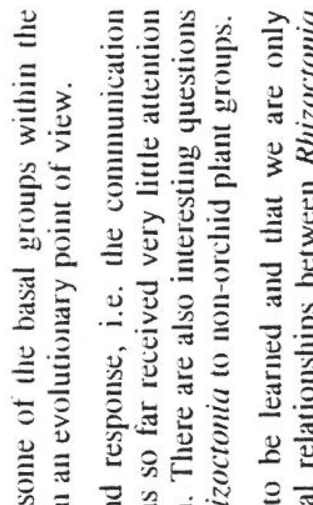

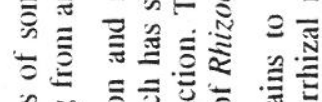

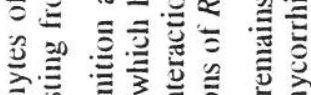

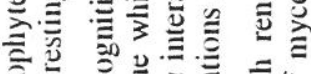

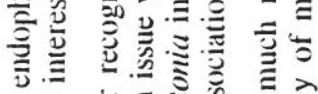

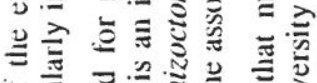

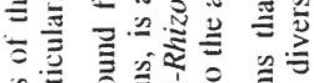

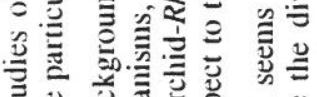

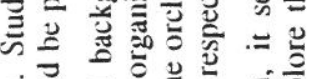

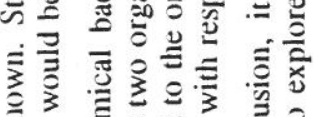

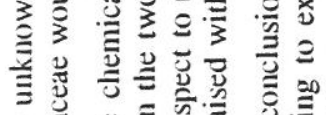

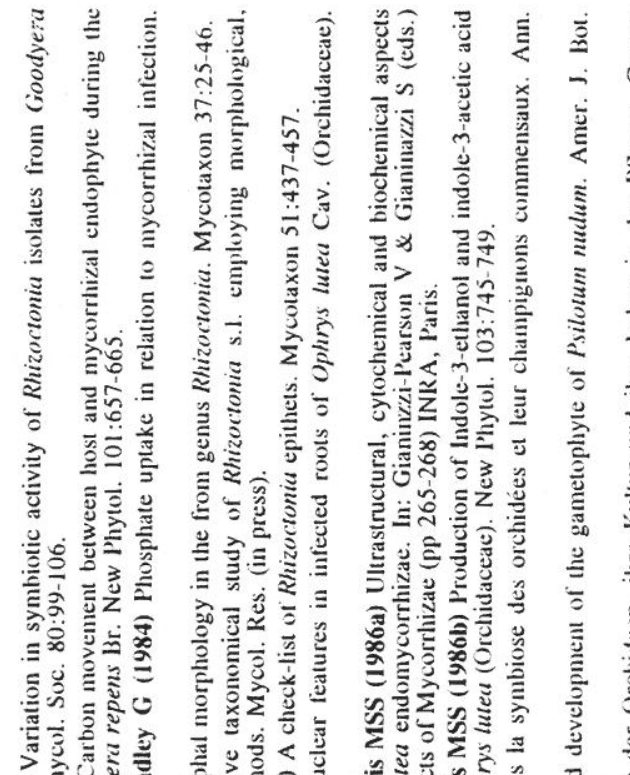

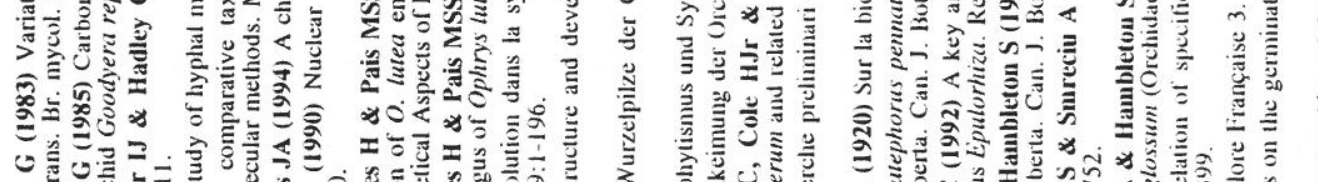

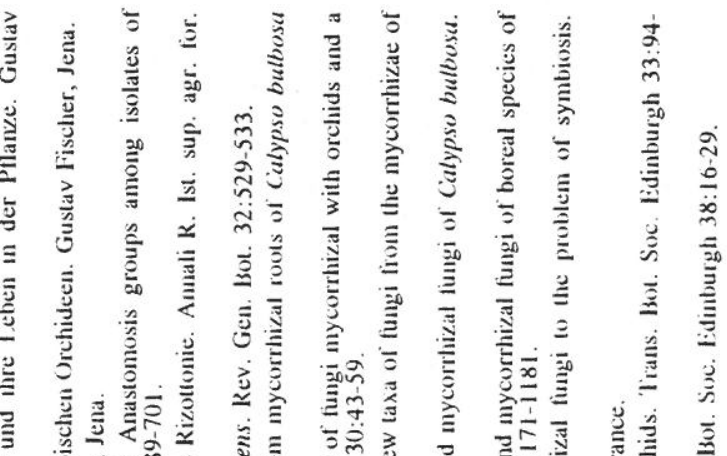

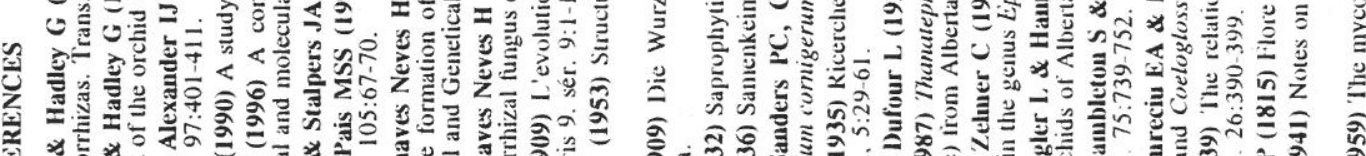

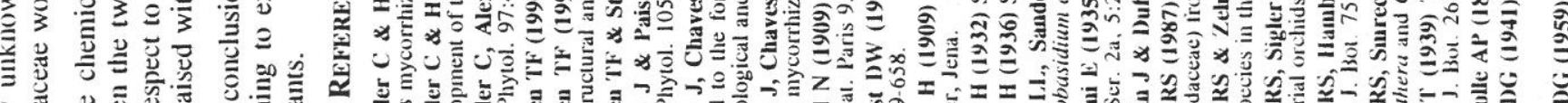

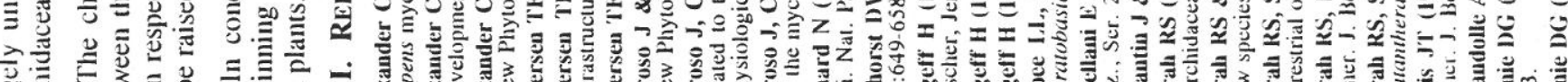

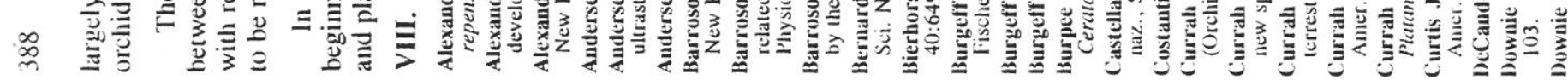



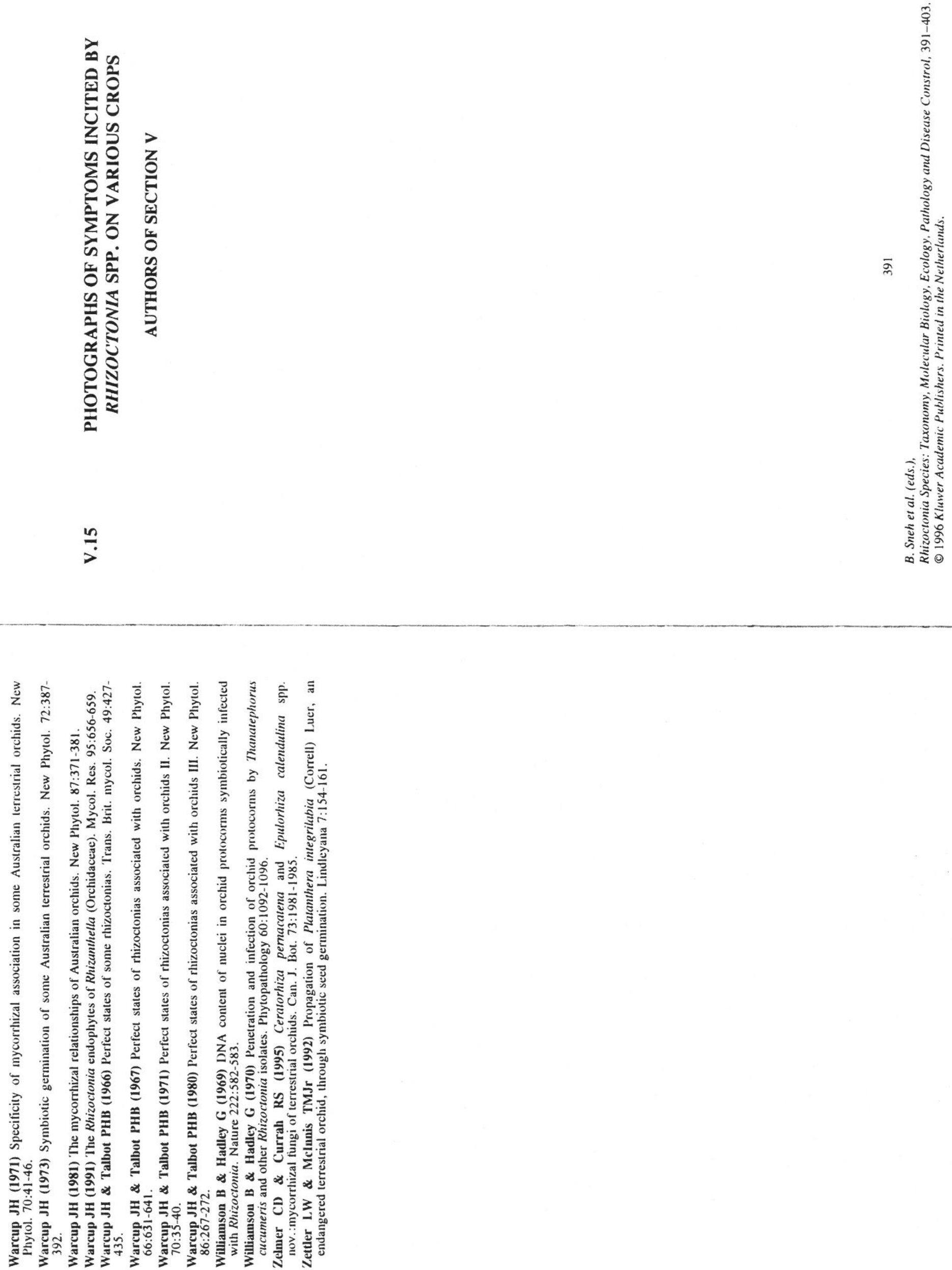